\title{
嗍珪酸ソーダ三成分系ガラスの揮発
}

\author{
新保 \\ （電京芝浦電父株式会社中央研究所）
}

\section{Volatilization Loss of Sodium Borosillicate Ternary Glasses}

\author{
By \\ Masaru SHINBO \\ (Tokyo Shibaura Electric Co., Kawasaki, Japan)
}

\begin{abstract}
Volatilization of glass components and formation of inhomogeneity in a glass melt during heating often result in striae, devitrification or fracture of the final glass products. Borosilicate glasses were known of their relatively high volatility at the temperatures of melting.

Volatilization loss at $1410^{\circ} \mathrm{C}$ was measured by thermo-balance method on the ternary $\mathrm{Na}_{2} \mathrm{O}-\mathrm{B}_{2} \mathrm{O}_{3}-\mathrm{SiO}_{2}$ glasses in the composition range of $0 \sim 40 \mathrm{Na}_{2} \mathrm{O}, 0 \sim 40 \mathrm{~B}_{2} \mathrm{O}_{3}$ and $60 \sim 85$ $\mathrm{SiO}_{2}$ in wt $\%$. The glass batches were prepared using purified sand and reagent grade chemicals and were melted in a platinum crucible in electric or gas-fired furnace. For the weight loss measurements, the glasses were held in small platinum crucible suspended in a vertical electric furnace. Results were as follows:

1) The amont of volatilization loss in a fixed time (for example, 1 or $6 \mathrm{hr}$ ) and with fixed $\mathrm{Na}_{2} \mathrm{O} / \mathrm{B}_{2} \mathrm{O}_{3}$ ratio decreased with increase of the $\mathrm{SiO}_{2}$ content, and for the constant $\mathrm{SiO}_{2}$ content the loss had its maximum at $\mathrm{Na}_{2} \mathrm{O} / \mathrm{B}_{2} \mathrm{O}_{3}$ ratio slightly lower than 1 . At these maxima, the losses were far greater than those of the corresponding $\mathrm{Na}_{2} \mathrm{O}$ - or $\mathrm{B}_{2} \mathrm{O}_{3}-\mathrm{SiO}_{2}$ binary glasses.

2) In almost all the glasses, the loss increased linearly with time. at the initial periods of heating. Generally, however, volatilization rates decreased with time.

3) Especially in glasses containing larger than $75 \mathrm{wt} \% \mathrm{SiO}_{2}$, crystallized surface layeres were formed in the course of the measurement, and in consequence, the volatilization rates decreased distinctly.

4) Under the condition of the measurements, thermal convection was observed in the crucible. Contrary to the case of glasses with relatively high $\mathrm{SiO}_{2}$ contents, in glasses with low $\mathrm{SiO}_{2}$ contents thermal convection took place distinctly that the considerable mixing phenomenon was observed in the glass melts.

5) One of the possible mechanisms which explain the results described in 1) and 2) is given in the following: At the initial periods of heating, volatilization rate is controlled by the evaporation of the volatile components from the melt to the atmosphere or by the flowing away of the gas atmosphere near the surface of the melt. Then, diffusion controlled mechanism or the effect of the lowering of the concentration of the volatile components in the melt gradually predominates, and lowers the volatilization rate.

6) Quatitatively, the relation between composition and volatilization loss showed a good agreement with the results of kolykov measuring at $1200^{\circ} \mathrm{C}$ (ref. 5). Quantitatively, however, the loss was 10 100 times larger than those by kolykov owing to the differences of the mesuring temperatures. Under the assumption that the initial volatilization rate is proportionate to the vapour pressure of glasses, it could be inferred that phase separation in the glass melts occur in the composition range with relatively low $\mathrm{Na}_{2} \mathrm{O}$ contents.
\end{abstract}

[Recieved June 8, 1966]

\section{1。緒言}

$\mathrm{B}_{2} \mathrm{O}_{3}$ を含むガラスを熔融する場合，ガラス表面から の成分の揮発が多いことはよく知られている。その結 果，ガラ久の組成が不均質となって，いわ㠴るすし，ぶ
つなどの久陮が生じ，また揮発物が酎火物を侵蝕して， 炉の寿命が縮まる。このような理由で， $\mathrm{B}_{2} \mathrm{O}_{3}$ を含むが ラスの揮発がしばしば測定された。

光学ガラスの基礎成分系として， $\mathrm{B}_{2} \mathrm{O}_{3}$ とアルカリ酸 
化物，アルカリ土類酸化物，あるい忙 $\mathrm{PbO}, \mathrm{CdO} \cdots . .$.

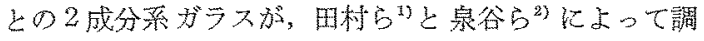

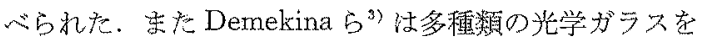
加熱して, 揮発量定测定した.

実用の器具用，要るい柱管球用の硼珪酸ガラスの揮発

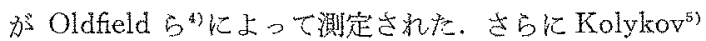
壮 $\mathrm{Na}_{2} \mathrm{O}-\mathrm{B}_{2} \mathrm{O}_{3}-\mathrm{SiO}_{2}$ 系ガラ又の揮発坴測定した。この

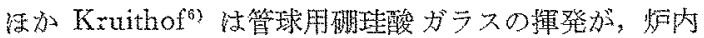
の雾国気に影響されること等調べた。

これらの研究によって試料組成，測定温度，時閒，炉 内䨌囲気や試料容器の形状などの測定条件, 試料ガラス

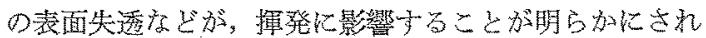

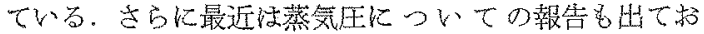
り，アルカリ，またはアルカリ土類酸化物一硼酸菜や， 各種契用ガラスが測定されだ い11

著老恬器具用及し管球用碚珄酸ガラスの揮発に関連し て, $\mathrm{Na}_{2} \mathrm{O}-\mathrm{B}_{2} \mathrm{O}_{3}-\mathrm{SiO}_{2}$ 系の基礎的なデ一夕を得る必要学 生じた.前述のように Kolykov'占この系索測定したが，

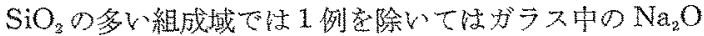

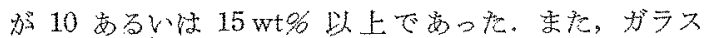
の構造に関する議論を目的としていたので,温度を1200 ${ }^{\circ} \mathrm{C}$ と比較的低く選び，表面変質層，执散層形成の影響 を避けよ5とした。しかし，突用がラスでは $\mathrm{Na}_{2} \mathrm{O}$ が しばしば $5 \%$ 以下であり，熔融温度以 $1600^{\circ} \mathrm{C}$ に近づ き，清澄部でも $1300^{\circ} \mathrm{C}$ 程度になることがある。おた，

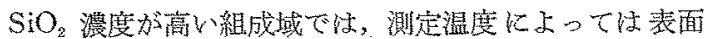

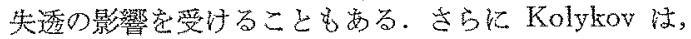
組成一揮発速度関係が単純でないことから，ある組成域 でや融液の相分嵟（分相）加要ること登推論した。これ が正しければ，温度の違いによる分相組战域の変化は， 組成一揮発速度関係を顕著に変える可能性がある。この 上らな理由で，実用上の目的には，組成域と測定温度と 変えてデー夕变補らことが必要と考えられた。さら

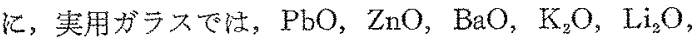
$\mathrm{Al}_{2} \mathrm{O}_{3}$ などが添加されるが，将来，これらの影響を的確 に求める場合にも，前記の系のデータ多基礎として必要 で京る。こ台の目的で，以下の実駼堂した。

\section{2. 試料}

表一戊示すように, $\mathrm{Na}_{2} \mathrm{O}-\mathrm{B}_{2} \mathrm{O}_{3}-\mathrm{SiO}_{2}$ 系のう云, $\mathrm{SiO}_{2}$ 60 85 wt\% の䉇困内で, 各成分学約 $5 \mathrm{wt} \%$ の間隔で 変えて 30 種のガラス学作った。原料に住，精製珪㔔と， 試薬特級の硯酸，䃆砂，炭酸ソーダ，硝酸ソーダを用い

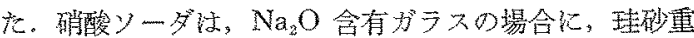
量の1/25 に相当するだけ使わ秃た。調合した原料窟ボ 一ルミルで潉合し，300 cc の白金坩堝で，4時間熔融し た。熔融温度はガラスにより $1300^{\circ} \sim 1650^{\circ} \mathrm{C}$ の間に選 び，主として炭化珪素発熱体の電気炉によったが，高温
Table 1. Composition of test glasses

\begin{tabular}{|c|c|c|c|c|}
\hline $\begin{array}{c}\text { Sumple } \\
\text { No. }\end{array}$ & $\mathrm{SiO}_{2}$ & $\begin{array}{l}\mathrm{Al}_{2} \mathrm{O}_{3} \\
+\mathrm{Fe}_{2} \mathrm{O}_{3}\end{array}$ & $\mathrm{~B}_{2} \mathrm{O}_{3}$ & $\begin{array}{l}\mathrm{Na}_{2} \mathrm{O} \\
+\mathrm{K}_{2} \mathrm{O}\end{array}$ \\
\hline 1 & 84.9 & 0.10 & 5.18 & 9,44 \\
\hline 2 & 84.6 & 0.10 & 9.66 & 5.44 \\
\hline 3 & 80.6 & 0.09 & - & 19.6 \\
\hline 4 & 81.1 & 0.10 & 4.98 & 13.7 \\
\hline 5 & 80.1 & 0.10 & 9.87 & 9.84 \\
\hline 6 & 79.7 & 0.10 & 14.9 & 5.22 \\
\hline 8 & 74.7 & 0.08 & 4.31 & 20.4 \\
\hline 9 & 74.0 & 0.07 & 10.7 & 14.9 \\
\hline 10 & 73.2 & 0.08 & 16.2 & 10.3 \\
\hline 11 & 74.4 & 0.09 & 20.0 & 5.31 \\
\hline 12 & 70.9 & 0.04 & - & 28.9 \\
\hline 13 & 69.6 & 0.09 & 4.95 & 24.8 \\
\hline 14 & 68.9 & 0.09 & 10.6 & 19.8 \\
\hline 15 & 69.6 & 0.08 & 15.8 & 14.3 \\
\hline 16 & 68.5 & 0.10 & 20.1 & 10.3 \\
\hline 17 & 68,9 & 0.08 & 24.5 & 5.69 \\
\hline 19 & 64.6 & 0.13 & 5.31 & 30.0 \\
\hline 20 & 64.5 & 0.11 & 10.2 & 25.2 \\
\hline 21 & 64.4 & 0.15 & 15.8 & 10.7 \\
\hline 22 & 63.8 & 0.13 & 20.8 & 15.3 \\
\hline 23 & 63.6 & 0.10 & 25.9 & 10.4 \\
\hline 24 & 62.8 & 0.10 & 29.8 & 7.31 \\
\hline 25 & 60.8 & 0.06 & - & 40.3 \\
\hline 26 & 60.8 & 0.11 & 4.87 & 34.2 \\
\hline 27 & 60.9 & 0.09 & 9.80 & 29.2 \\
\hline 28 & 60.2 & 0.15 & 14.8 & 24.8 \\
\hline 29 & 60.3 & 0.10 & 20.3 & 19.3 \\
\hline 30 & 60.1 & 0.11 & 24.8 & 15.0 \\
\hline 32 & 60.3 & 0.22 & 33.9 & 5.63 \\
\hline 33 & 57.7 & 0.11 & 41.6 & 0.11 \\
\hline
\end{tabular}

在要する場合 $\left(\mathrm{SiO}_{2} 80 \mathrm{wt}\right.$ \% 以上）は方不炉定用いた。 熔融中に，石英ガラス棒で数回擋拌し，その後ステンレ ス鋼板上に流し出し，急冷した。ガラスを瑪琝乳鉢で粉 研し，7〜20 メッシュの粒をとり，メタノールで細粉を 除き，110 $\mathrm{C}$ で乾燥し，デシケータ中に貯えた。原料珪

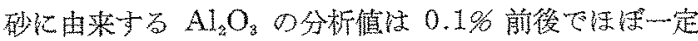
であり， $\mathrm{K}_{2} \mathrm{O}$ 注 $0.05 \%$ 以下であった。

ほ为に参考ないし予備実験として，実用硼珄酸ガラス TX60も用いた。これはタンク炉で熔融されたすので， 分析組成は 表-2 の上らで苏った。

Table 2. Composition of commercial borosilicate Terex-60 glass $(w t \%)$

Sample $\quad \mathrm{SiO}_{2} \quad \mathrm{~B}_{2} \mathrm{O}_{3} \quad \mathrm{Al}_{2} \mathrm{O}_{3} \quad \mathrm{Na}_{2} \mathrm{O} \quad \mathrm{K}_{2} \mathrm{O} \quad \mathrm{Li}_{2} \mathrm{O} \quad \mathrm{As}_{2} \mathrm{O}_{3}$

$\begin{array}{llllllll}\mathrm{TX} 60 & 77.9 & 14.6 & 2.2 & 5.0 & 0.3 & 0.2 & 0.2\end{array}$

\section{3. 測定装置と方法}

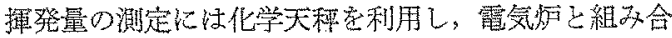
わせて作った熱天秤家使った。炉江 2 重スパイラル形宸 化珪素発熱体で加熱され，炉の内管の大きさは $35 \mathrm{~mm} \phi$ (内径) $\times 400 \mathrm{~mm}$ であった，温度は電子管式自動平衡型 記録調節温度計により，on-off で調節された，炉の上方 に天和置き，1 mm $\phi$ の白金線で，白金容器を釣り下 げた。容器の大きさは上部が $22 \mathrm{~mm} \phi$, 底部が $16 \mathrm{~mm}$, 深さ $16 \mathrm{~mm}$ で，ガラス試料 $5.00 \mathrm{~g}$ 前後を大れた。 
試料は化学天秤で $0.1 \mathrm{mg}$ の精度で容器にはかり取ら れ，熱天秤に鈎り下り゙られて，測定温度に保持された炉 内に雨入された。この時を時間の原点として, 試料の重 量減を測った。 測定終了後は, 試料を炉内で放泠し, 固 化後のガラスについて，表面積を測定した。

測定温度结 $1410^{\circ} \mathrm{C}$ 亿選えだ。炉内の温度は, on-off 調節のため $\pm 10^{\circ} \mathrm{C}$ の変動が亦ったが, その平均温度に ついていえば，虾中央の長さ $5 \mathrm{~cm}$ の部分にわたり，士 $5^{\circ} \mathrm{C}$ 以内の等温带方要り，ここに試料容器上，その底面 から $1 \mathrm{~cm}$ 離して熱電詨の接点とを置いた。

重量測定は振動法によったが，炉内雾囲気の対流

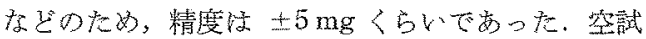
験では，容器や白金線の重量变化は辡められず，ま た，揮発物の白金線への凝縮量は測定精度以下であ ot.

炉内雾国気の流通が揮発量に大きく影響すること が予備実験で知られたので，炬底部から，シリ为方 ルで乾燥し、ニクロA線在淃いた石英唯ラス管内で 予熱された空気を, $30 \mathrm{cc} / \mathrm{min}$ の速度で送った。 の空気法重量測定中には止められた，測定所要時間 は約 3 分で步った。重量は 1 時間ごとに 6 時間まで 測られた。

加熱初期の揮発の挙動家調べるために二，三の試料に ついて蛙登隇量の測定間隔老 15 分とし， $2 \sim 3$ 時間 継続した。立たこの場合は空気の通気速度を20１50 $\mathrm{cc} / \mathrm{min}$ の籁囲内で変化させて, 測定值を求めた。

試料容器内の熱的対流の有無とその程度上を定性的に

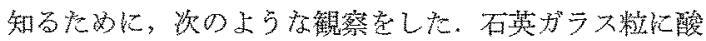
化コバルトを附着させ, 酸水素バーナ一で熔融し, 約 1 $\mathrm{mm}$ くらいの着色粒子を得た。これを容器内のガラス表 面の中央に浮汃心，1時間加熱後に静かに取り出し，固 化したガラス塊（厚さ $2 \mathrm{~mm}$ ) の切断片在作り, 着色し たすじの分布を, 観察した。容器内ガラスは, 重嘼減測 定の場合と同じ条件で加熱された，また，同じ目的で， 重量減測定老終った試料内の不均質を投影法で観察し， または表面附近での屈折率変動の分布を測った場合があ る。

\section{4. 測 定結 果}

単位表面積当りの揮発量と時間との関你学図-1〜3に 示した. 多くの場合, 㭙閒が経つ之揮発速度が減少し た. $\mathrm{SiO}_{2}$ が $75 \mathrm{wt} \%$ 以上のむのは, 特にこのことが顥 著で，数時間後に法揮発量が注ばー定になった。これら は，いずれも表面に結晶尿が生じて姯り，その面樍は，

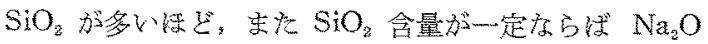

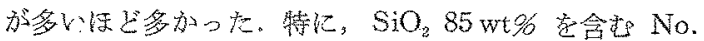

1 妿ラスは, 内部なで結晶化していた。

$\mathrm{Na}_{2} \mathrm{O}-\mathrm{SiO}_{2}$ 就よび $\mathrm{SiO}_{2}-\mathrm{B}_{2} \mathrm{O}_{3}$ の2成分系ガラス住, 同じ $\mathrm{SiO}_{2}$ 含量の 3 成分系ガラスより, 揮発量がかなり 少なく, 揮発速度もほぼ一定のままであった。

図-2 に加熱 1 時間後及び 6 時閒後の筆位面積あたり

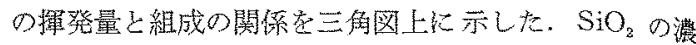
度が高いほど揮発量が少なく，一定 $\mathrm{SiO}_{2}$ 濃度で住
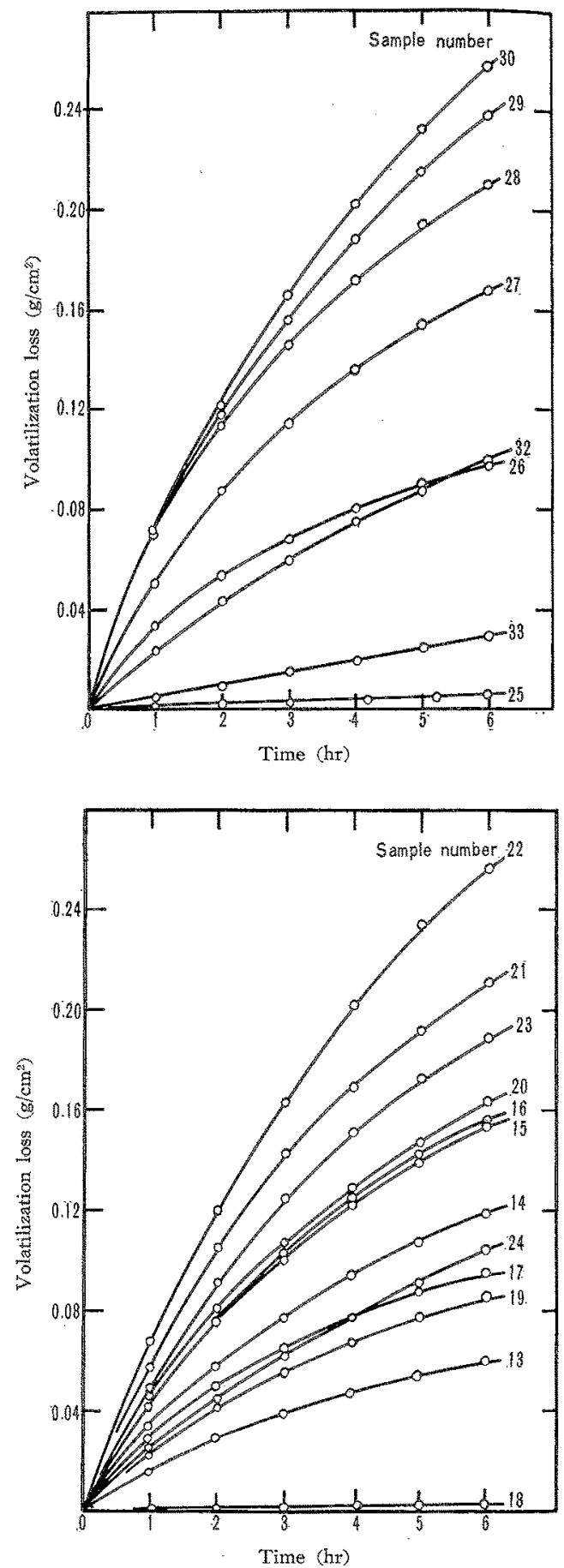


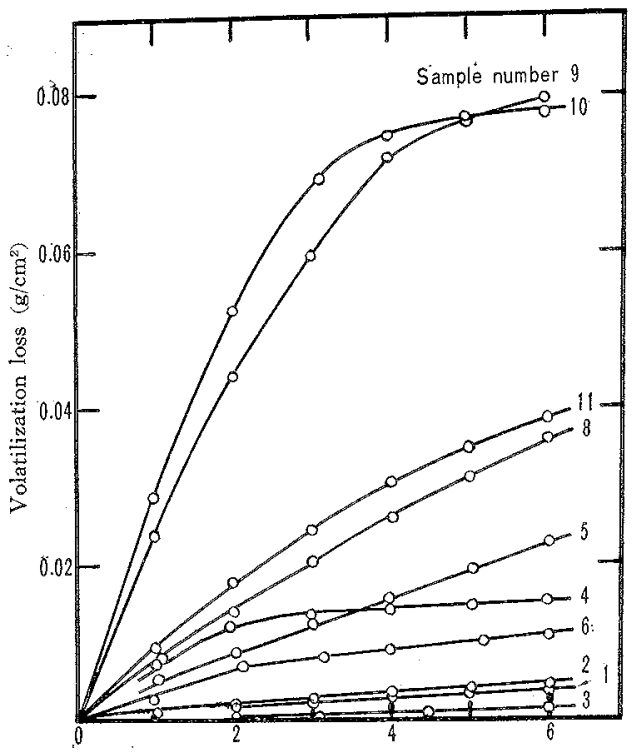

Time (hr)

Fig. 1. Time vs. volatilization loss (per unit surface area) curves of test glasses at $1410^{\circ} \mathrm{C}$. $\mathrm{SiO}_{2}$ concentration of the glasses are a) 60 , b) 65 $\sim 70$ and c) $75 \sim 85 \mathrm{wt} \%$ respectively.

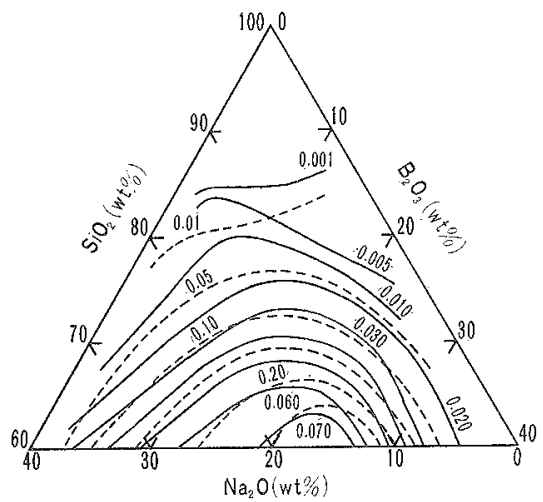

: after heating for $1 \mathrm{hr}$,

: after heating for $6 \mathrm{hr}$.

Fig. 2. Belation between composition (wt $\%$ ) and volatilization loss ( $\mathrm{g} /$ surface area $\mathrm{cm}^{2}$ ) of the test glasses.

$\mathrm{Na}_{2} \mathrm{O} / \mathrm{B}_{2} \mathrm{O}_{3}$ の比が1またはそれよりやや小さいところ で最大になる。これは，Kolykov ${ }^{5)}$ の結果(図-3)と定性 的に似た点も㐫るが，揮発量極大の位置に差が見られ， 測定温度の差に刘总て, 揮発量も 10 100 倍多い。

$\mathrm{SiO}_{2}$ の濃度が 60 及び $70 \mathrm{wt} \%$ の試料 No. 29 , No. 15 と TX 60 について, 加熱初期の揮発量と時閒の関 你，及び通気空気の流速の影響を図-4 に示寸、いずれ もはじめの 1 時間ほどは揮発量と時間とが直線関係とな り, No. 29, No. 15 法流速の増加と共に直線の公配が 増加する．TX 60 の場合は初期重量のバラッキに起因す

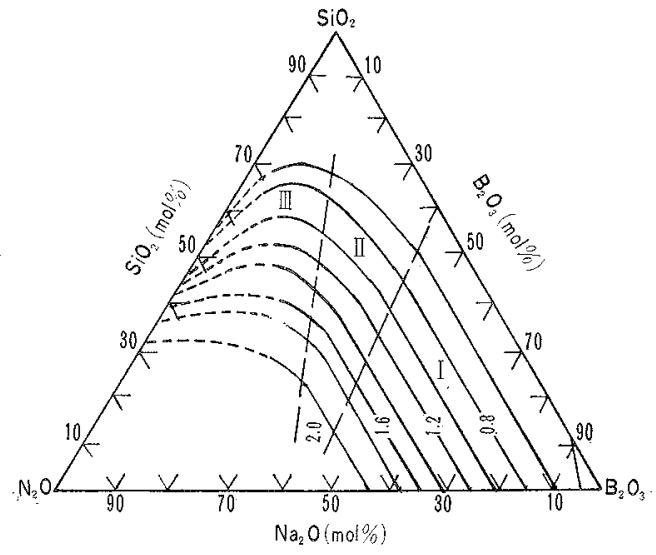

Fig. 3. Volatilization rate of glasses in ternary $\mathrm{Na}_{2} \mathrm{O}$ $\mathrm{B}_{2} \mathrm{O}_{3}-\mathrm{SiO}_{2}$ system at $1200^{\circ} \mathrm{C}$ by Kolykov. Composition of glasses : mol \%, volatilization rate: mg loss per surface area $\left(\mathrm{cm}^{2}\right)$ per $\mathrm{hr}$.

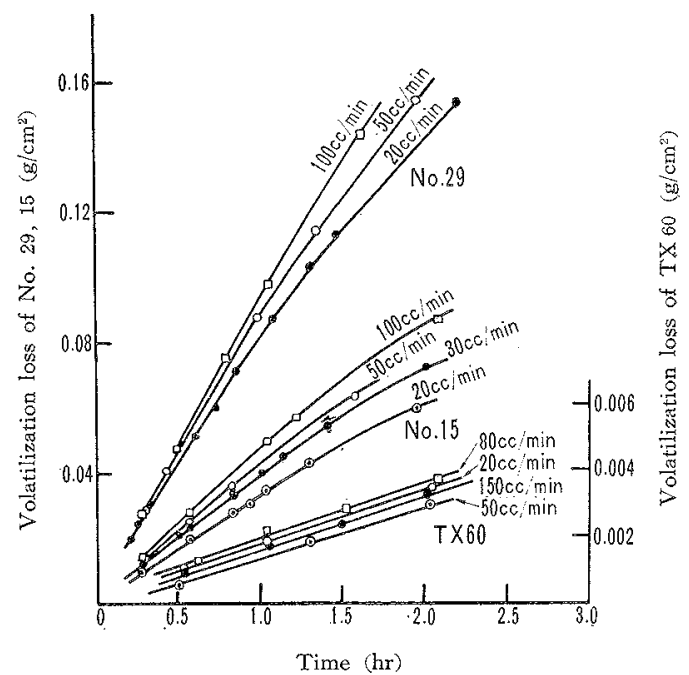

Fig. 4. Time vs, volatil ization loss (per unit surface area) relations of some experimental and commercial glasses at initial period of heating with flow rate of air in the furnace as a parameter.

ると考えられる揮発量の変化はあるが，直線の勾配は流 速の影響を受けないようである。

試料中の対流の状沉を知るための実験の結果を, 図 -5 に例示した. $\mathrm{SiO}_{2}$ 含量の多いガラスで法, 石英粒と, コ バルトで活染されたガラスとは，表面に局在するだけで あった. $\mathrm{SiO}_{2}$ が $60 \mathrm{wt} \%$ くらいの低い含量のガラスで は, 石英粒が底へ引き込まれ，またガラス全体がコバル トで着色していて，対流による混合作用があったことを 示した。このような場合には, 表面の変質層の存在を屈 折率変化から検出しょらとしても，できないことが多か ot。

一方，実用ガラスでは， $1500^{\circ} \mathrm{C}$ 加熱にともなら表面 


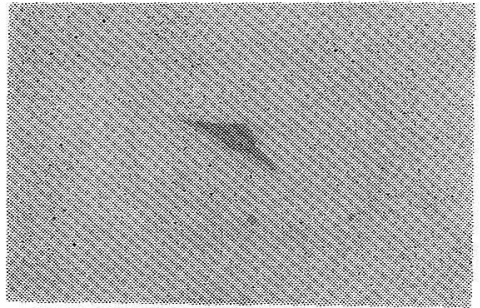

Sample No. 1

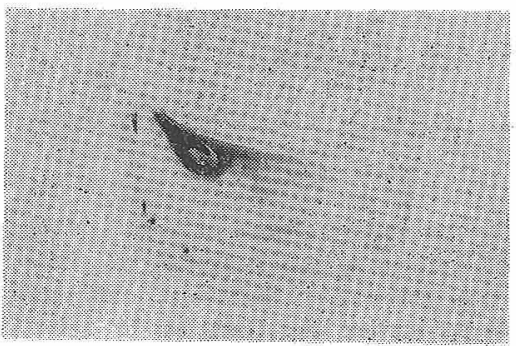

No. 4

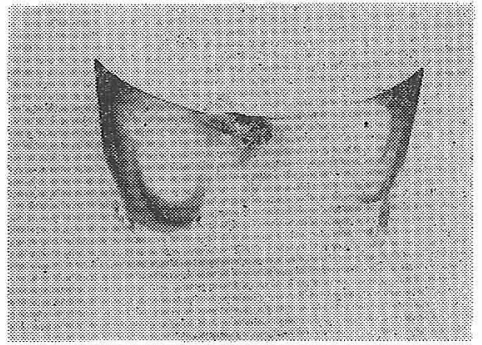

No. 6

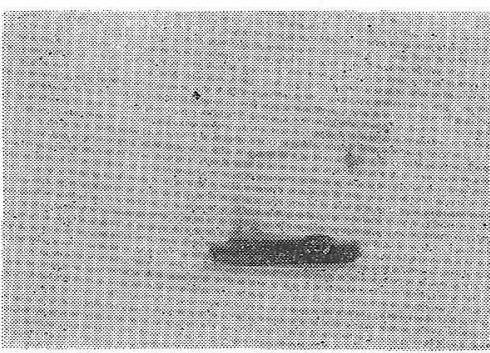

No. 8

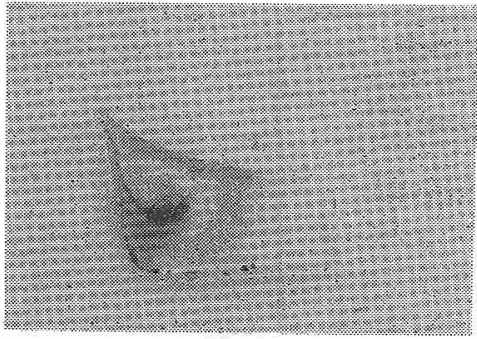

No. 15

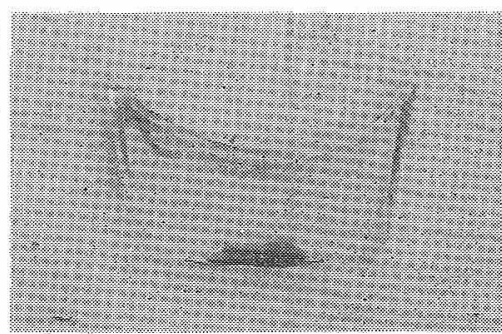

No. 22

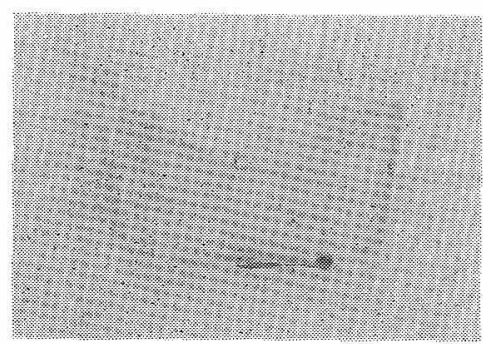

No. 24

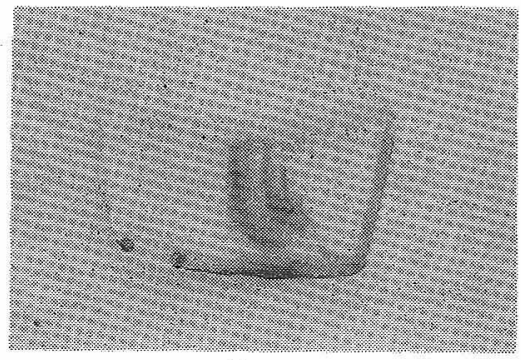

No. 27

Fig. 5. Results of the test for observing the effect of thermal convection in the glass samples during soaking at $1410^{\circ} \mathrm{C}$ for $1 \mathrm{hr}$.

Distance from surface $(\mathrm{mm})$

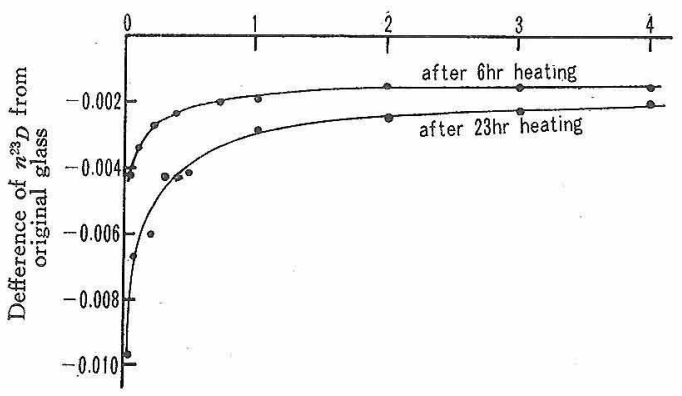

Fig. 6 Distribution of refractive index near the surfaces of Terex-60 glass after heating at $1500^{\circ} \mathrm{C}$ for 6 and $23 \mathrm{hr}$.

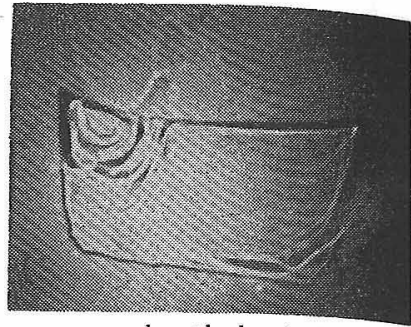

ather $6 \mathrm{hr}$ heating

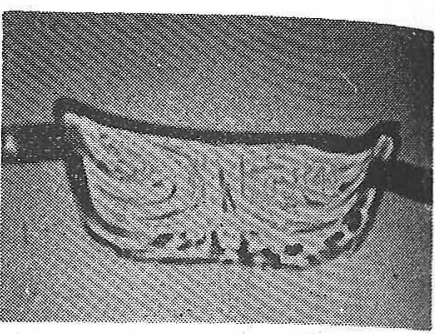

after $23 \mathrm{hr}$ heating

Fig. 7. Forming of striae by heating the commercial Terex-60 glass at 1500 ${ }^{\circ} \mathrm{C}$ for 6 and $23 \mathrm{hr}$ (pho. tographed by "Schattenverfahren" of polis. hed cross sections)

層の形成が屈折率测定で検知さ れ（図一6)，またそれが刘流で 引き込まれて，不均質を発生す ることが観察された。（図-7）

\section{5. 考察}

揮発速度を決定する要因とし ては，たとえば次のよらなもの が挙げられよら。

1. ガラス 表面附近の 雾井気 中にある揮発物質が流れ去る速 度

2.ガラス 表面から雾囲気中

ヘの揮発物質の離脱速度

3. ガラス融液内部から 表面への揮発物質の抬散速度

これらの場合を現象的に見ると，次のような結果が予 期される。

1.では，揮発量は蒸気圧が高く，䨌囲気の流速が大き いほど多く，流速が一定ならば時間 $t$ とはほぼ比例する であろう。

2.では，揮発速度はガラス中の揮発物質濃度が大きい と多く，場合によってはほぼ比例するであるう：揮発に よる濃度変化も考慮すれば $Q=k_{1}\{1-\exp (-\beta t)\}, k_{1}$, $\beta$ : 常数, $Q$ : 揮発量となり， $t, Q$ が小さい範囲では $Q$ は $t$ に比例する。しかしながら，Q は流速には無関倸 
のはずである。

3.では，よく知られているように，ガラスの深さが無 限大の場合には， $Q=k_{2} \sqrt{D t}, D$ : 桩散係数, $k_{2}$ : 常数の 関係䜑劣。

ガラスの梁さが有限でも，揮発物签の全量が $1 / 2<ら$ いに減るまでは，この式が近似的に成立吉る ${ }^{12)}$.

次に，前記のような理想化された経過を乱すものとし ては, 融液内の対流と, 融液表面の結晶層生成がある.

A．刘流は，拡散層の形成索妨げ，融液内の揮発物濃 度の不均一をなくすよらに働く、そのため, 航散の寄与 革小さくし，1.または 2 . の機構の寄与孝堌す。

B、結晶層が生成し，この中での揮発物質の拡散が律 速となるなら洁，1。〜3，の機構によるそれぞれの $t$-揮 発量関伭吕，一般に汇成立しなくなる、造膜反応 ${ }^{13)}$ の場

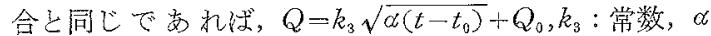
: 拡散係数と同じ次元を持つ係数， $t_{0}$ : 結晶層が形成さ れる灾での時間， $Q_{0}: t_{0}>t>0$ の期間の揮発量，という 関係吕成立する。

これらの機構のらち，どれが実際に起きているが， 難加し、問題である。たとえば $\sqrt{t}$-揮発量曲線を書く

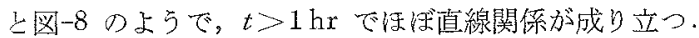
この直線は，原点を通過しないが，插大当初の温度加立 だ十分上昇しない時間として，10〜15 min を $t$ 加ら差 し引けば，揮発量がほぼ $\sqrt{t}$ に比例することになる. しかし， $t<1 \mathrm{hr}$ では，実験的に法揮発量は $t$ に比例し

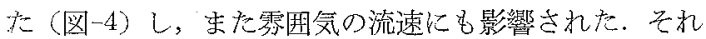

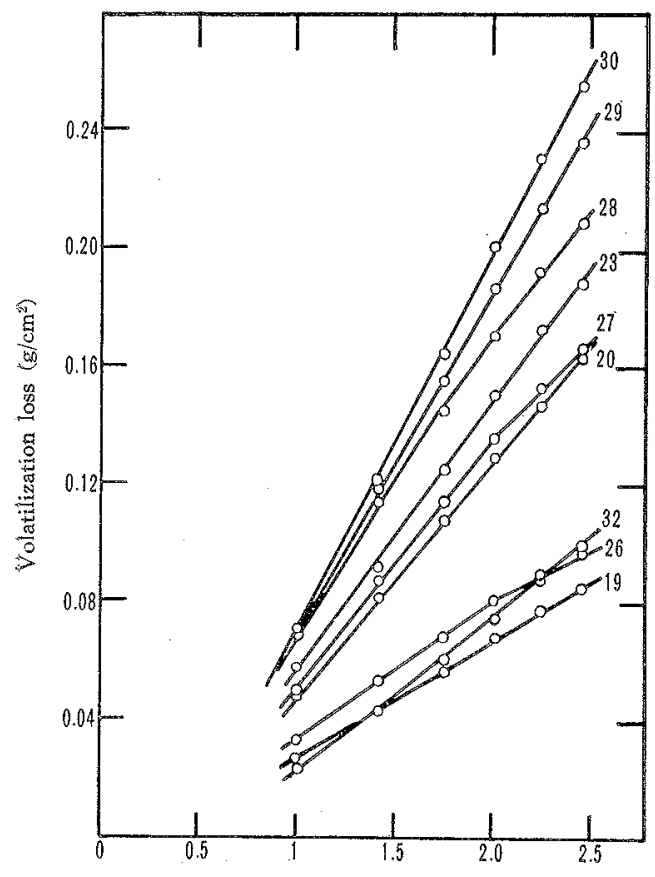

Squar root of heating time $(\sqrt{t})$

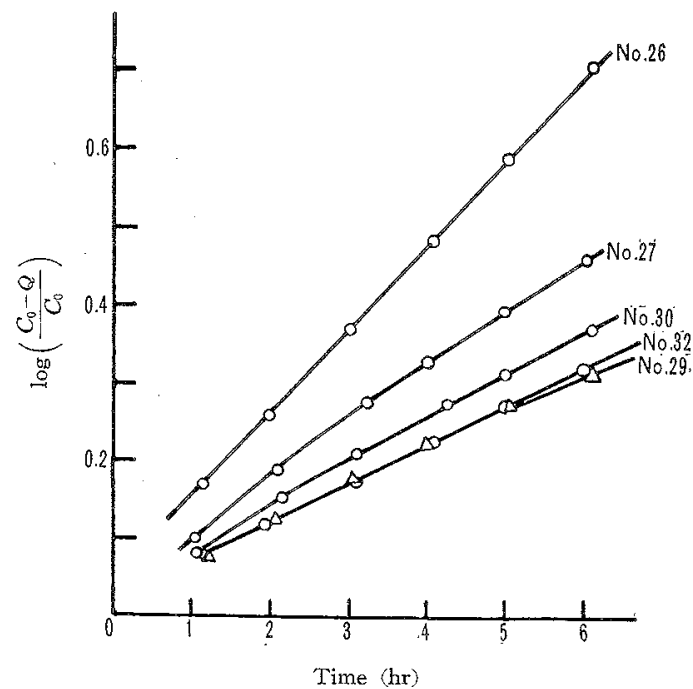

Fig. 9. Examples of time vs. $\log \frac{C_{0}-Q}{C_{0}}$ of some glasses $C_{0}$ : initial quantity of $\mathrm{Na}_{2} \mathrm{O} \cdot \mathrm{B}_{2} \mathrm{O}_{3}$ in glass samples, $Q$ : assumed volatilization loss of $\mathrm{Na}_{2} \mathrm{O} \cdot \mathrm{B}_{2} \mathrm{O}_{3}$ (total loss minus assumed loss from glass composition other than $\mathrm{Na}_{2} \mathrm{O}$. $\mathrm{B}_{2} \mathrm{O}_{3}$ )

故，単純な搪散律速で注ないと考えられる。

またたとえば， $\mathrm{SiO}_{2}$ の含量の少ないガラスに颃いて 揮発するものが $\mathrm{Na}_{2} \mathrm{O} \cdot \mathrm{B}_{2} \mathrm{O}_{3}$ だと仮定し ${ }^{7111}$ ，ガラスが $\mathrm{Na}_{2} \mathrm{O} \cdot \mathrm{B}_{2} \mathrm{O}_{3}$ と $\mathrm{Na}_{2} \mathrm{O}-\mathrm{SiO}_{2}$ 系ガラス，または $\mathrm{Na}_{2} \mathrm{O}$. $\mathrm{B}_{2} \mathrm{O}_{3}$ と $\mathrm{B}_{2} \mathrm{O}_{3}-\mathrm{SiO}_{2}$ 系ガラスの混合物と考える. 全揮発

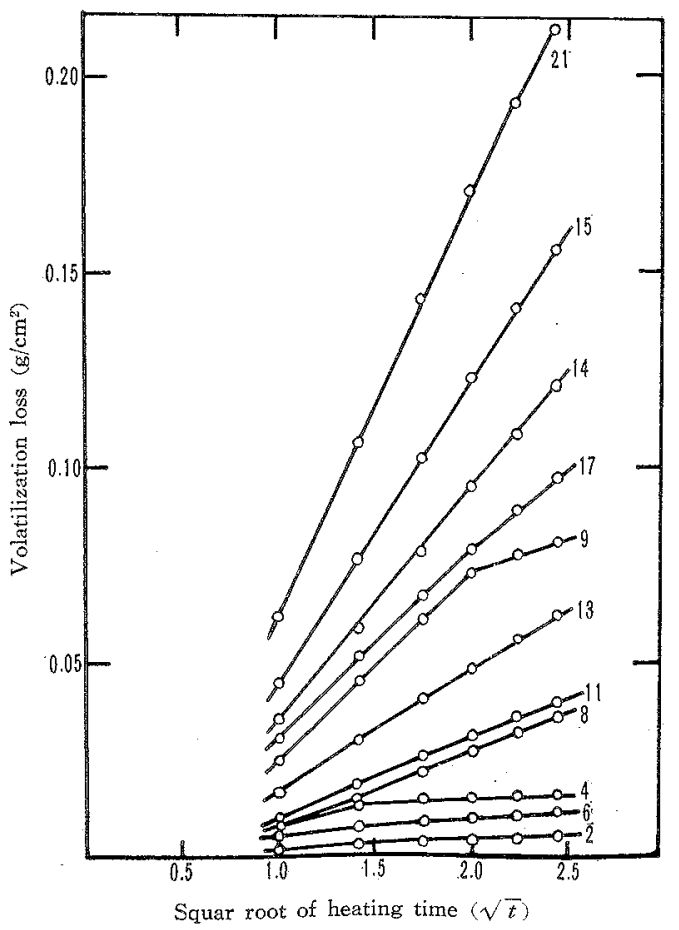

Fig. 8. Examples of $\sqrt{\text { time }}$ vs. volatilization loss plot of the glasses. a) $60-65 \mathrm{wt} \% \mathrm{SiO}_{2}$, b) $65-85 \mathrm{wt} \% \mathrm{SiO}_{2}$ 
量を $Q_{T}, \mathrm{SiO}_{2}$ を含む 2 成分系ガラスからの揮発量(図)

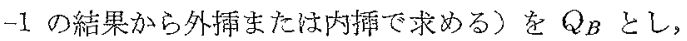
初为 $\mathrm{Na}_{2} \mathrm{O}_{0} \mathrm{~B}_{2} \mathrm{O}_{3}$ の全量を $C_{0}, Q$ を $Q_{T}-Q_{B}$ と置 いて, 時間と $\log \left\{\left(C_{0}-Q\right) / C_{0}\right\}$ との関係をとると图-9 のようになり、ほ淔線に近い，それゆ光，蒸発過程が

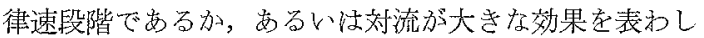
ているかのように見える。

この実験の場合には刘流が存在することが示された

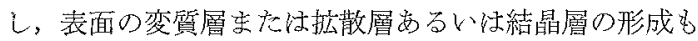
諗められた場合があった（図一5,6,7)。

從って，揮発量法，始的に列举した上亏原多くの過程 によって，決定される上考光なければならない，多少の 推測をすれば，加熱初期に活機構１と２亿よって主とし て律速され，ついで抬散律速に移るのではないだるら か.この後に, 結晶層が生長寸れば揮発速度江著しく小 さく抑えられるで为万ら。拡散層は, 表面が $\mathrm{Na}_{2} \mathrm{O}$ や $\mathrm{B}_{2} \mathrm{O}$ を失って高粘度になるので, 対流によって内部に 近い層は引き込まれて, ガラスの不均質の原因になる が，表面層は長く残留して揮発速度を決定する作用を続 けるであろう。

なお， Oldfield ${ }^{4)}$ は，実用喼珪酸ガラスで $\sqrt{t}$ と揮発 量とが比例するとし，拡散律速だとした。 Kolykoviうは， $\mathrm{Na}_{2} \mathrm{O}-\mathrm{B}_{2} \mathrm{O}_{3}-\mathrm{SiO}_{2}$ 系ガラスの $1200^{\circ} \mathrm{C}$ での揮発速度が蒸 気任に比例すると考え, 蒸気压と組成, 融液の構造との 関䋆を諭じている、蒸発，拡散の两方を考慮した理論 は，功刀らが導いた ${ }^{14\}}$.

図-2 に示された結果恃，Kolykovis のそれを高 $\mathrm{SiO}_{2}$ 組成域一外插したもの（図-3）と，定性的に似ている。 また, 一定の $\mathrm{SiO}_{2}$ 含量の時, $\mathrm{Na}_{2} \mathrm{O} / \mathrm{B}_{2} \mathrm{O}_{3}$ 重量比が 1 前 後で極大となる点では，田村ら ${ }^{1)}$ が $\mathrm{Na}_{2} \mathrm{O}-\mathrm{B}_{2} \mathrm{O}_{3}$ 系で得 た結果に近い。ただし，田村らが $\mathrm{Na}_{2} \mathrm{O} / \mathrm{B}_{2} \mathrm{O}_{3}=1$ で認

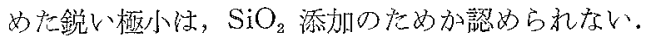

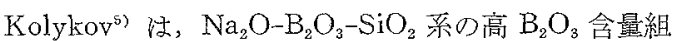
成域 (図-3I) で, 等揮発速度 (等蒸気圧) 曲線が $\mathrm{SiO}_{2}$ $-\mathrm{B}_{2} \mathrm{O}_{3}$ 軸に平行であることから，この部分で融衸が2 相 に分離するとした。本䒠験での初期の揮発速度が蒸気压 に比例するものであり，かつ Kolykov の用いた前提や 推論が正しければ, 図-2 の高 $\mathrm{B}_{2} \mathrm{O}_{3}$ 組成域では, 融液 中で相分離が起きているといえる、また等 $\mathrm{SiO}_{2}$ 濃度で の揮発量最大吕， $\mathrm{Na}_{2} \mathrm{O} / \mathrm{B}_{2} \mathrm{O}_{3}$ 比の小さい方へ移ってい るのは，測定温度が高いために，分相組成域が狭くなっ たためとの解釈もできる。しかし，これらの点てついて は，別の方面から確認する必要が女るら。

ガラス表面に結晶相が形成されると，塞用ガラスの場 合には製品の久陷を引き起こすので，重要な問題であ る. Morey ${ }^{15}$ が決为た $\mathrm{Na}_{2} \mathrm{O}-\mathrm{B}_{2} \mathrm{O}_{3}-\mathrm{SiO}_{2}$ 系の相平衡図 から推算すると, $1400^{\circ} \mathrm{C}$ を液相温度とするのは, $\mathrm{SiO}_{2}$ が約 $85 \mathrm{wt} \%$ の組成に相当する。これに対応する No.1
ガラスは，揮発量が僅かであり，測定後は大部分が結晶 化していた。これより $\mathrm{SiO}_{2}$ 含量が低いガラスでも，搪 散層形成につれて表面の $\mathrm{SiO}_{2}$ 濃度が增加して, 液相温 度が測定温度を越え，結局任結晶化すると考えられる。 保持温度を低くすれば，揮発量は少なくなるが，一方だ はより $\mathrm{SiO}_{2}$ 含量の少ない組成のもの量で結晶化し，ま た粘度増加のため表面層が長く停留し，発達卞るである 5 .

\section{6. 総 括}

$\mathrm{Na}_{2} \mathrm{O}-\mathrm{B}_{2} \mathrm{O}_{3}-\mathrm{SiO}_{2}$ 系の, $\mathrm{SiO}_{2}$ が $65 \sim 85 \mathrm{wt} \%$ の組成 域のガラスを, $1410^{\circ} \mathrm{C}$ で加熱, 熔融した時の揮発量を 測定した。測定結果注次のようであった。

1. 一定時間内の揮発量は, $\mathrm{Na}_{2} \mathrm{O} / \mathrm{B}_{2} \mathrm{O}_{3}$ 比が一定なら， $\mathrm{SiO}_{2}$ の堌加ととも亿減少した。 $\mathrm{SiO}_{2}$ が一定ならば， $\mathrm{Na}_{2} \mathrm{O} / \mathrm{B}_{2} \mathrm{O}_{3}$ 比が 1 上りやや小さい部分で, 揮発量が極 大になり，ここで法 $\mathrm{Na}_{2} \mathrm{O}-\mathrm{SiO}_{2}$ また注 $\mathrm{B}_{2} \mathrm{O}_{3}-\mathrm{SiO}_{2} 2$ 成 分系ガラスに比べて，たと充ば 10 倍程度の高い值を示 した。

2. 加熱初期には，いずれのガラスでも，ほぼ一定の 速度で揮発した。しかし多くの場合, 時間の経過と乞も に揮発速度が減少し始めた。

3. 特に, $\mathrm{SiO}_{2}$ が $75 \mathrm{wt} \%$ 以上の試料で惊，測定中 (6 時間) 内に結晶層が 表面に発生し，撜発速度が著し く滅少した。

4. 本実験の条件下では，ガラス中に熱刘流が起きて いた，その程度は， $\mathrm{SiO}_{2}$ 含量が多いガラスでは僅かだ が， $\mathrm{SiO}_{2}$ 含量が少ないガラスでは,かなりの混合作用を 持っくらいに影著であった。

5. 1. と2.の結果を説明する揮発機構として可能な ものの一例は, 次のようであらう：加熱初期に注，融液 表面加ら雾国気认の揮発物質の離脱，あるい注表面附近 にある揮発物質を含有した霑国気ガスの流失などにより 速度が決定される。つで，融液中での，揮発物質の表 面一の拡散が律速する段階にらつるか，また注がラス中 の揮発物濃度が低下古るなどの理由で，揮発速度が小さ くなって行く.

6. 組成々揮発量との関係沙，Kolykov の $1200^{\circ} \mathrm{C}$ だ の測定結果と定性的に法似て招り，初期の揮発量之蒸気 圧との比例性を仮定すれば，たとえば $\mathrm{Na}_{2} \mathrm{O}$ の少ない 組成域での融液の相分離などが推測される。揮発量自体 は，測定温度の差に対応して，本報の場合の方が 10 100 倍くらいも大きかった。

\section{文献}

1) Y. Tamura, Y. Oishi, Y. Hamano, Sympsium sur la Fussion de Verre 543 (1958).

2）泉谷，浜村，原，大工試季報，9，16 (1958).

3) L.X. Demkina, L.D. Novozhilova, Glass and Ceramics 20, 312 (1965). 
4) L.H. Oldfield, R.W. Wright, Glass Tech, 3, 59 (1962); Advanees in Glass Technology 35 (1963).

5) J.A. Kolykov, The Structure of glass I 184 (1958).

6) A.M. Kruithof, C.M. Lagrow, L. Groot, Sympsium sur la Fussion de Verre 515 (1958).

7) A. Büchler, J.B. Berkowitz-Mattuck, J. Chem. Phy. 30, 286 (1963).

8) D.L. Hildenrand, W.F. Hall, N.D. Potter, J. Chem. Phy. 30, 296 (1963).

9) C.E. Adams, J.T. Quan, J. Phy. Chem. 70, 331 (1966).
10) P.E. Blackburn. A. Büchler, J. Phy. Chem. 88, 4250 (1965).

11) C. Kröger, L. Sörnström, Glastech. Ber. 38, 313 (1965).

12) J. Crank, The Mathematics of Diffusion 21 (1956).

13）広田, 反灾䢞度 (共立全畫) 152 (1960).

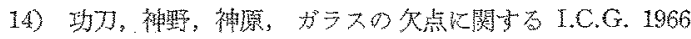

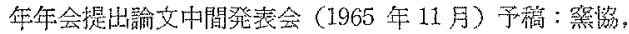
73 [10] C 571 (1965).

15) G.W. Morey, J. Soc. Glass Tech. 35, 270 (1951),

(6/8/1966 受付)

\title{
As-S 系ガラスの赤外線吸収スペクトルについて
}

\author{
（磢化物ガラスの物性と構造 I）
}

\author{
土橋正二・矢野晃朗・小松俊憲・足立桂一郎 \\ (神戸大学理学部)
}

\section{On the Infrared Absorption Spectra of As-S Glasses}

By

Shoji TSUCHIHASHI, Teruo YANO, Toshinori KOMATSU and Keiichiro ADACHI

(Department of Chemistry, Faculty of Science, Kobe University, Rokkodai, Kobe)

Arsenic trisulfide glass is of interest as a material of higher refractive index, transparent in the infra-red and having low melting characteristics.

The structure of arsenic trisulfide glass has been studied by $\mathrm{X}$-ray diffraction techni$q^{1} e^{1)}$, and the data indicate a short range order arrangements of the atoms similar to those in the crystalline orpiment structure. However, there have been very few reports of structure determinations of sulfide glasses which have higher content of sulfur than that of $\mathrm{As}_{2} \mathrm{~S}_{3}$. In undertaking to provide the necessary structural information, the infra-red absorption of samples with vorious compositions was examined.

$\mathrm{As}_{2} \mathrm{~S}_{3}$, one of raw materials, is synthesized by passing purified $\mathrm{H}_{2} \mathrm{~S}$ gas into $6 \mathrm{~N}-\mathrm{HCl}$ solution of purified $\mathrm{As}_{2} \mathrm{O}_{3}$, and dried at temperatures below $100^{\circ} \mathrm{C}$, but it was very difficult to remove the small content of $\mathrm{Cl}^{-}$included in $\mathrm{As}_{2} \mathrm{~S}_{3}$. This crude $\mathrm{As}_{2} \mathrm{~S}_{3}$ formed black-red glasses. To obtain blight red glasses, $A s_{2} \mathrm{~S}_{3}$ must be purified by vacuum distillation.

In oftaining the glass, at first, the raw materials were mixed up and melted one hour at $360^{\circ} \mathrm{C}$ by using porcelain crucible, but in this case it was found by infra-red absorption method that the glass contains some oxygen impurities (Fig. 2, Table. 3). Therefore, the method of preparation of the glass samples was changed in the following way.

Sufficiently pure elements that exactly, weighted for yielding 5-30 grammes of glass were stored in the thick-walled pyrex-type glass ampoules, which were then evacuated and sealed while still under vacuum. The ampoules were heated up to $600^{\circ} \mathrm{C}$ or $450^{\circ} \mathrm{C}$ in a furnace, and then quenched or allowed to cool down to room temperature. Infra-red absorption measurements between $1000-400 \mathrm{~cm}^{-1}$ were made through polished parralle-sided discs, approximately $0.2-2$ millimeters thick, or through very thin film sandwitched by $\mathrm{KBr}$ plates, using a Hitachi-Perkin Elmer Model 125 and/or Japan Spectroscopic DS-402 Grating Infrared Spectrometer or Hitachi Infracord.

The results obtained were shown in the Table. 4 anb 5 .

Kolomiets and Pavlov suggested ${ }^{5}$ that the absorption band appeared at around $800 \mathrm{~cm}^{-\mathrm{x}}$ is due to $\mathrm{As}_{2} \mathrm{Se}_{3}$. To ascertain their suggestions, the As-S glass samples contained $\mathrm{Se}$ (No. 7) were prepared, yet it resulted in no indication of absorption band at around $800 \mathrm{~cm}^{-1}$. According to the study by Tanaka et al. ${ }^{10)}$ on arsenic-sulfur glasses prepared by evaporation under normal pressure, it was suggested that the absorption band appered at around 800 